IRA-International Journal of Management \& Social Sciences

ISSN 2455-2267; Vol.04, Issue 01 (2016)

Institute of Research Advances

http://research-advances.org/index.php/RAJMSS

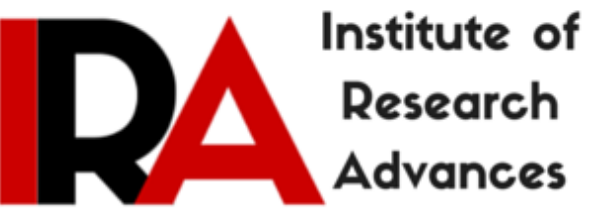

\title{
The Forecasting Power of the Volatility Index: Evidence from the Indian Stock Market
}

\author{
${ }^{1}$ Surya Bahadur G. C. \\ Assistant Professor, School of Business, Pokhara University, Nepal. \\ ${ }^{2}$ Ranjana Kothari \\ Assistant Professor, Amity University, Gurgaon, India.
}

DOI: http://dx.doi.org/10.21013/jmss.v4.n1.p21

\section{How to cite this paper:}

Bahadur G. C., S., \& Kothari, R. (2016). The Forecasting Power of the Volatility Index: Evidence from the Indian Stock Market. IRA-International Journal of Management \& Social Sciences (ISSN 2455-2267), 4(1). doi:http://dx.doi.org/10.21013/jmss.v4.n1.p21

(C) Institute of Research Advances

\section{(c) EY-NC}

This works is licensed under a Creative Commons Attribution-Non Commercial 4.0 International License subject to proper citation to the publication source of the work.

Disclaimer: The scholarly papers as reviewed and published by the Institute of Research Advances (IRA) are the views and opinions of their respective authors and are not the views or opinions of the IRA. The IRA disclaims of any harm or loss caused due to the published content to any party. 


\begin{abstract}
Stock market volatility is a measure of risk in investment and it plays a key role in securities pricing and risk management. The paper empirically analyzes the relationship between India VIX and volatility in Indian stock market. India VIX is a measure of implied volatility which reflects markets' expectation of future short-term stock market volatility. It is a volatility index based on the index option prices of Nifty. The study is based on time series data comprising of daily closing values of CNX Nifty 50 index comprising of 1656 observations from March 2009 to December 2015. The results of the study reveal that India VIX has predictive power for future short-term stock market volatility. It has higher forecasting ability for upward stock market movements as compared to downward movements. Therefore, it is more a bullish indicator. Moreover, the accuracy of forecasts provided by India VIX is higher for low magnitude future price changes relative to higher stock price movements. The current value of India VIX is found to be affected by past period volatility up to one month and it has forecasting ability for next one-month's volatility which means the volatility in the Indian stock markets can be forecasted for up to 60 days period.
\end{abstract}

Keywords: Implied volatility, India VIX, Investor fear gauge, Volatility forecasting.

\title{
1. Introduction
}

Forecasting of stock market volatility is useful for investors as it is an indicator of risk inherent in stock market investment. Volatility index is a popular tool for predicting the future short-term market volatility (Sarwar, 2012). The first volatility index (VIX) was introduced by Chicago Board of Options Exchange (CBOE). After that, the index has also been introduced in several developed and emerging markets. VIX is calculated on the basis of implied volatility derived from option prices. These volatility indices are measure of market expectation of volatility over a short-term future period (Giot, 2004; Becker et al., 2009; Bagcchi, 2012). Often referred to as the 'investor fear gauge', the VIX aims to track the market expectation of volatility, giving an indication about how nervous the market is about the future. It reflects investors' consensus view of future expected stock market volatility (Ryu, 2012). When the VIX level is low, it implies that investors are optimistic and complacent rather than fearful in the market, which indicates that investors perceive no or low potential risk. On the contrary, a high VIX reading suggests that investors perceive significant risk and expect the market to move sharply in either direction. VIX generally moves inversely to stock markets, rising when stocks fall and vice-versa. Globally known as a 'fear index', VIX is actually one of the best contrarian technical indicators in the world (Rhoads, 2011).

VIX offers great advantages in terms of trading, hedging and introducing derivative products on this index (Satchell and Knight, 2007). Investors can use volatility index for various purposes. First, it depicts the collective consensus of the market on the expected volatility and being contrarian in nature helps in predicting the direction. Investors therefore could appropriately use this information for taking trading positions. Second, Investors whose portfolios are exposed to risk due to volatility of the market can hedge their portfolios against volatility by taking an off-setting position in VIX futures or options contracts (Banerjee and Sahadev, 2006). Third, investors could also use the implied volatility information given by the index, in identifying mispriced options (Jian and Tian, 2007). Fourth, short sale positions could expose investors to directional risk. Derivatives on volatility index could help investors in safeguarding their positions and thus avoid systemic risk for the market (Lu et al., 2012). Fifth, based on the experience gained with the benchmark broad based index, sector specific volatility indices could be constructed to enable hedging by investors in those specific sectors (Dixit et al. 2010).

In India, the National Stock Exchange (NSE) introduced a volatility index for the Indian market in April 2008 called the India volatility index (India VIX). It is a measure of implied volatility calculated by the NSE from near-term at-the-money options on the CNX Nifty 50 index, and the methodology to compute the implied volatility is identical to the one adopted for the calculation of CBOE VIX. It represents the level of price volatility implied by the option markets, not the actual or historical 
volatility of the index itself. This volatility is meant to be forward looking and is calculated from both calls and puts option premiums (Thenmozhi and Chandra, 2013). NSE launched India VIX Futures for traders who are willing to bet on volatility on February $26^{\text {th }}, 2014$. The underlying asset for the VIX futures contact is the India VIX. India VIX Futures enables participants to more easily hedge, trade and arbitrage the expected volatility. Despite the usefulness of India VIX, prior studies on the volatility index are scanty. Hence, the main purpose of the study is to make an assessment of forecasting ability of India VIX, and hence, its usefulness for predicting short term stock market volatility. Moreover, it also attempts to investigate the relationship of India VIX index with the volatility of the Indian stock market, to explore the association between these two measures of financial market volatility and to understand the directional influence between them.

\section{Review of Literature}

The volatility implied by option prices is often considered a reflection of option traders' view of future market volatility of the underlying assets (Fleming, 1997). It is often believed that option traders are better informed; thus, the implied volatility outperforms historical volatility in forecasting future realized volatility (Whaley, 2000). Partially motivated by the informational role of optionimplied volatilities, the Chicago Board of Option Exchange (CBOE) began to publish an implied volatility index in 1993. The VIX Index is a key measure of market expectations of near-term volatility conveyed by S\&P 500 (SPX) stock index option prices. There are two versions of the volatility index, an old one and a new one. The old VIX was renamed VXO in September 2003 which is computed based on the prices of a portfolio of 30-calendar-day out-of-the-money SPX calls and puts with weights being inversely proportional to the squared strike price. The current VIX is based on a different methodology and uses the S\&P 500 European style options rather than the S\&P100 American style options. Despite these two major differences the correlation between the levels of the two indices is about 98\% (Zhang, 2006). The CBOE has also introduced volatility derivative products based on the index.

Corrado and Miller (2005) compare the forecast quality of implied volatility indexes to historical volatility, and they find VIX outperforms historical volatility in forecasting future realized volatility. Similar result is found by Zhang (2006), who show that VIX outperforms GARCH volatility estimated from the S\&P 500 index returns. A very important feature of VIX is that VIX tends to be higher when the stock market drops, for example, VIX was particularly high during the last quarter of 2008, when the stock market tumbled. Whaley (2009) explains why VIX is a useful "market fear gauge": when stock market is expected to fall, investors will purchase the S\&P 500 put options for portfolio insurance. The more investors demand, the higher the option prices. As option price is a monotonic increasing function of volatility, VIX will increase when the S\&P 500 index option prices increase. According to a recent report by the S\&P 500 Corporation, VIX is very useful in forecasting the direction of future market movements, particularly when movement is large. These findings highlight the potential benefits of adding VIX as a new asset class to hedge portfolio risks.

Numerous articles have examined the forecasting power of VIX since the Index was introduced. Taking it as the respective set of implied volatilities, Frinjns et al. (2010) conclude that the unbiasedness of VIX cannot be rejected over the sample period from 1986 to 2000 and therefore contains information of future volatility. Poon and Granger (2003) conclude that the construction of VIX is a good tool for model-based forecasting. In contrast, the study of Becker et al. (2006) rejects the notion that it contains any information for volatility forecasting. However, after a more detailed study, specifically examining the forecast performance of VIX, Becker and Clemens (2007) conclude that it is a superior predictor of market volatility. Based on arguments on the forecasting performance of VIX and the financial markets turmoil in 2008, Whaley (2009) argues that it is forward-looking measurement of S\&P index volatility, representing expected future market volatility over the next 30 calendar days. Hung et al. (2009) find that combining VIX into a GARCH-type model can enhance the one-step-ahead volatility forecasts while evaluating the forecasting with different types of loss functions. 
In the Indian context, Kumar (2012) and Bagchi (2012) studied the India VIX and its relationship with the Indian stock market returns. Kumar (2012) finds negative association between the India VIX and stock market returns and the presence of leverage effect significantly around the middle of the joint distribution. Bagchi (2012) constructs value-weighted portfolios based on beta, market-to-book value and market capitalisation parameters, and reports a positive and significant relationship between the India VIX and the returns of the portfolios. Banerjee and Kumar (2011) find that the implied volatility measures: the CBOE VIX, the KOSPI volatility index, and the India VIX are sufficiently good predictors of realized volatility in the S\&P100 index (U.S.A.), the KOSPI 200 index (Korea), and the Nifty index (India) respectively. Kumar (2010) finds that the volatility index exhibits volatility persistence, mean reversion, negative relationship with stock market movements and positive association with trading volumes. However, the negative relationship between market returns and volatility is observed only during market declines. Thenmozhi and Chandra (2013) examine the asymmetric relationship between the India VIX and stock market returns, and demonstrate that Nifty returns are negatively related to the changes in the India VIX levels; in the case of high upward movements in the market, the returns on the two indices tend to move independently. When the market takes a sharp downward turn, the relationship is not as significant for higher quantiles. They also find that the India VIX captures stock market volatility better than traditional measures of volatility, including the ARCH/GARCH class of models.

\section{Data and Methodology}

\subsection{Nature of Data}

The study is based on time series data comprising daily closing values of CNX Nifty 50 index of National Stock Exchange (NSE), India. NSE is selected as it has the highest turnover and number of trades in equity and derivatives segment in India. The CNX Nifty is a well diversified 50 stock index accounting for 23 sectors of the Indian economy. It is used for a variety of purposes such as benchmarking fund portfolios, index based derivatives and index funds. The index represents about $66.85 \%$ of the free float market capitalization of the stocks listed on NSE as on December $31^{\text {st }}, 2015$. Moreover, as the study focuses on study of India volatility index which is developed by NSE, the index is natural choice for the study. India VIX's historical data is available from March 02, 2009. Hence, the study periods comprises of 1656 daily observations from March 2009 to December 2015. All the required data on Nifty Index and India VIX is collected from the NSE database.

\subsection{Measures of Stock Market Volatility}

The measures of stock market volatility can be grouped in two major classes; the realized or historical volatility measures and implied or forward volatility measures. The variables used in the study as the indicator of stock market volatility are as follows:

\subsubsection{Annualized Returns (AR)}

Market return is a simple measure of fluctuations in stock prices. Higher the fluctuations, higher are be the returns. The daily market returns of the stock market indices used in the study is computed as logarithmic difference as follows:

$$
R_{t}=\log \left[\frac{I_{t}}{I_{t-1}}\right] \times 100
$$

Where, $R_{t}$ is return in time $t . I_{t}$ is the value of stock market index in time $t$ and $I_{t-1}$ is one period lagged value of stock market index. The daily return is annualized by multiplying with the number of trading days in a year. 


\subsubsection{Annualized Rolling Standard Deviation (ARSD)}

Standard deviation is a popular measure of realized stock market volatility and risk of investment. It is a measure of variability found by taking square root of the average of squared deviations from the mean. The study uses the following standard formula for computation of standard deviation:

$$
\sigma=\sqrt{\left(\frac{1}{n-1}\right) \sum\left(R_{t}-\bar{R}\right)^{2}}
$$

Where, $\mathrm{R}_{\mathrm{t}}$ is daily market return at time $\mathrm{t}$ and $\bar{R}$ is the average market return during the period. The annualized standard deviation is calculated as $[\sigma \times \sqrt{252}]$. The number of trading days in a year is 252. The standard deviation used in the study are calculated as annualized rolling standard deviation (ARSD) with lead and lag time periods of 21 trading days (one month), 10 trading days (half month), and 5 trading days (one week).

\subsubsection{India VIX - The Implied Volatility Measure}

India VIX (IVIX) is a volatility index computed by NSE based on the order book of Nifty Options. For this, the best bid-ask quotes of near and next-month Nifty options contracts which are traded on the F\&O segment of NSE are used. IVIX indicates the investor's perception of the market's volatility in the near term (Sarwar, 2012). A high IVIX value would suggest that the market expects significant changes in the Nifty, while a low IVIX value would suggest that the market expects minimal change. It has also been observed that historically, a negative correlation exists between the two (Chakrabarti, 2015; Kumar, 2010; Karmakar, 2003). The IVIX reflects the expected movement in the Nifty index over the next 30-day period, which is then annualized. For example, if IVIX is 16.8025 , this represents an expected annualized change of $16.8025 \%$ over the next 30 days. Volatility Index is different from a market index like Nifty 50 . Nifty index measures the direction of the market and is computed using the price movement of the underlying stocks whereas. While Nifty is a number, IVIX is denoted as an annualized percentage (Aggrawal et al., 1999). Although IVIX is often called the "fear gauge", a high IVIX is not necessarily bearish for stocks. Instead, it is a measure of market perceived volatility in either direction, including to the upside. IVIX uses the computation methodology of CBOE, with suitable amendments to adapt to the Nifty options order book. The formula used in the IVIX calculation is:

$$
\sigma^{2}=\frac{2}{T} \sum \frac{\Delta K_{i}}{K_{i}^{2}} e^{R T} \mathrm{Q}\left(K_{i}\right)-\frac{1}{T}\left[\frac{F}{K_{0}}-1\right]^{2}
$$

Where, $\mathrm{T}=$ time to expiration, $\mathrm{K}_{\mathrm{i}}=$ strike price of $\mathrm{i}^{\text {th }}$ out-of-the-money option, $\mathrm{R}=$ risk-free interest rate to expiration, $\mathrm{Q}\left(\mathrm{K}_{\mathrm{i}}\right)=$ midpoint of the bid ask quote for each option contract with strike $\mathrm{K}_{\mathrm{i}}, \mathrm{F}=$ forward index taken as the latest available price of Nifty future contract of corresponding expiry and $\mathrm{K}_{0}=$ first strike below the forward index level $\mathrm{F}$.

\subsubsection{Percentage of Days of Volatility (PODV)}

While the VIX provides a look at market expectations for future volatility, it does not specifically separate downside volatility out of its calculation. Neither does standard deviation, which, as mentioned above, does not consider investors' expectations and assumes a normal distribution of returns. In an effort to neutralize some of the disadvantages of using the VIX or standard deviation, investors can use another potential proxy for stock market volatility, the "percentage of days of volatility." The percentage of days of volatility is a measurement of the percentage of days in a period when an index level goes up or down a certain percentage or more. There are advantages to using the percentage of days of volatility measure over standard deviation or the VIX. This measurement summarizes the actual percentage changes in an index, instead of providing an estimate of the distribution based on the mean and variance. Using it the downside and upside volatility can be shown separately by displaying the proportion of falling days in a period separately from the percentage of 
increasing days. More emphasis tends to be placed upon negative returns than positive returns because investors fear a loss more than they celebrate a gain. Hence, PODV is a volatility measure which distinguishes between positive and negative volatility in order to take risk aversion into account. The study uses following formula for calculation of PODV:

$$
\operatorname{PODV}=\frac{\sum(\Delta \mathrm{I} \geq \mathrm{k} \%)}{\mathrm{N}}
$$

Where, $\Sigma(\Delta \mathrm{I} \geq \mathrm{k} \%)$ is the sum of days in $\mathrm{N}$ period in which the percentage change in market index $(\Delta \mathrm{I})$ is more than or equal to $\mathrm{k} \%$. The $\mathrm{N}$ used in the study is 21 trading days or 1 month. The $\mathrm{k} \%$ is 1 , 2 and 3 percentage points. The percentage of days of volatility used in the study is computed for three cases. First, the percentage of days in a month when market goes up or down by k\% (i.e. $1 \%, 2 \%$ or $3 \%)$. Second, the percentage of days in a month when market goes up by $\mathrm{k} \%$. Third, the percentage of days in a month when market goes down by $\mathrm{k} \%$.

\subsection{Model Specification}

The relationship between forward volatility and spot IVIX value is investigated using the following models. The models examine the predicting ability of IVIX for future short term stock market volatility. The first model is used to investigate if IVIX has ability to predict future volatility as measured by forward rolling standard deviation of market returns.

$$
\operatorname{ARSD}_{t+n}=\alpha+\beta_{1} I V I X_{t}+\sum_{i=1}^{j} \gamma_{i} A R S D_{t \pm n}+\mu_{t}
$$

Where, ARSD is annualized rolling standard deviation for forward $\mathrm{n}$ days. The forward days (n) are 5, 10 and 21 trading days representing future one week, half month and one month periods respectively. The forward stock market volatility measure ARSD is expected to depend on spot IVIX value in time " $t$ " and its autoregressive lagged values. The value of $\mathrm{j}=3$.

The second model is used for assessing the predictive ability of current IVIX value for forward $n$ period percentage of days of volatility (PODV). It also makes comparison of predictive ability of IVIX for both upward and downward market movements of different magnitudes.

$$
\operatorname{PODV}_{t+n}( \pm k \%)=\alpha+\beta_{1} I V I X_{t}++\mu_{t}
$$

Where, $\mathrm{n}$ is 5,10 and 21 trading days. $\mathrm{K} \%$ is 1,2 and 3 percentage movement in Nifty index.

$$
I V I X_{t}=\alpha+\sum_{i=1}^{j} \beta_{i} A R S D_{t-n}+\mu_{t}
$$

The current value of IVIX is also expected to be determined by previous level of stock market volatility. Hence, the third model analyzes the impact of past ' $n$ ' days volatility on spot IVIX value. The lagged $\mathrm{n}$ periods used are 5, 10 and 21 trading days. The $\mu_{t}$ represents random error term.

\section{Results Discussion}

Table I presents correlation coefficient of IVIX with different measures of volatility. The volatility measures are average returns, and annualized rolling standard deviation of daily returns. Both of these indicators measure the fluctuations in stock prices and hence are indicators of stock market volatility. 
As IVIX is a measure of future short term expected volatility, it is expected to be correlated with forward or leading standard deviation up to one month period.

Table I: Correlation Matrix of Stock Market Volatility Indicators

\begin{tabular}{|c|c|c|c|c|c|c|c|}
\hline NIFTY 50 & AR & IVIX & $\begin{array}{c}\text { ARSD } \\
(-21)\end{array}$ & $\begin{array}{c}\text { ARSD } \\
(-10)\end{array}$ & $\begin{array}{c}\text { ARSD } \\
(-5)\end{array}$ & $\begin{array}{c}\text { ARSD } \\
(+21)\end{array}$ & $\begin{array}{c}\text { ARSD } \\
(+10)\end{array}$ \\
\hline AR & 1 & & & & & & \\
\hline IVIX & 0.011 & 1 & & & & & \\
\hline ARSD (-21) & $0.101^{* *}$ & $0.769^{* *}$ & 1 & & & & \\
\hline ARSD (-10) & $0.123^{* *}$ & $0.711^{* *}$ & $0.859^{* *}$ & 1 & & & \\
\hline ARSD (-5) & $0.131^{* *}$ & $0.617^{* *}$ & $0.698^{* *}$ & $0.816^{* *}$ & 1 & & \\
\hline ARSD (+21) & 0.003 & $0.741^{* *}$ & $0.609^{* *}$ & $0.586^{* *}$ & $0.526^{* *}$ & 1 & \\
\hline ARSD (+10) & -0.005 & $0.703^{* *}$ & $0.584^{* *}$ & $0.575^{* *}$ & $0.532^{* *}$ & $0.860^{* *}$ & 1 \\
\hline ARSD (+5) & 0.025 & $0.606^{* *}$ & $0.522^{* *}$ & $0.525^{* *}$ & $0.489^{* *}$ & $0.697^{* *}$ & $0.814^{* *}$ \\
\hline
\end{tabular}

Correlation is significant at the 0.01 level (2-tailed). AR=Average Returns, ARSD = Annualized Rolling Standard Deviations of Daily Returns and IVIX = India Volatility Index

The correlation matrix reveals that IVIX is highly correlated with annualized rolling standard deviation with lag 21 days as indicated by positively high and significant correlation coefficient of 0.769. Moreover, IVIX is also highly correlated with annualized rolling standard deviation with leading 21 days. The results reveal that although VIX is an indicator that predicts volatility in stock market up to one month in future, the IVIX is found to be more correlated with volatility of lag one month. It indicates that the past volatility is important factor that affects investors' expectation regarding future volatility. However, IVIX has a significant correlation of 0.741 with annualized rolling standard deviation for leading or future one month (i.e. 21 working days). Hence, IVIX is found to be a useful indicator for predicting future short term stock market volatility in India. The figures and table presented in the appendices which illustrate the trend of IVIX and realized stock market volatility measures also indicate that IVIX and ARSD are associated. The IVIX is also correlated both leading and lagging annualized standard deviations for half month and weekly period. The correlations are stronger for longer period (i.e. one month and half month) and significantly positive. The results imply that the value of IVIX is associated with both past and future short term volatility up to one month period. Moreover, IVIX is found to be more useful in predicting volatility of future 21 days and 10 days as compared to 5 days.

Table II illustrates mainly the correlation coefficients between IVIX and different percentage of days of volatility (PODV) measures. The correlations matrix contains correlations of IVIX with PODV up or down, PODV up, and PODV down by 1, 2 and 3 percent. The PODVs are computed using one month forward (i.e. 21 working days) daily Nifty returns. IVIX is considered predictor of future stock market movements; hence, it should be correlated with future one month percentage of days of volatility. Additionally, IVIX is also referred to as "fear gauge", so, it should reflect correlations with PODV down. The results reveal that IVIX is positively correlated with all of the PODV measures. It means that IVIX is related with percentage changes in short term (i.e. one month) stock prices, both, up and down movements. Hence, IVIX is both bearish and bullish indicator. Moreover, IVIX is more correlated with past price movements as shown by relatively higher correlations of PODV up or down by 1,2 and 3 percent. IVIX has the greatest correlation of 0.77 with PODV up by 2 percent. It indicates that IVIX is more efficient in forecasting upward movement in stock prices as compared to downward movement. Hence, IVIX is found to be more a bullish indicator. The second highest correlation of 0.71 is found between IVIX and PODV up or down by 2 percent. Although, the correlations of IVIX with PODV down are significant and positive, they are relatively lower. The results demonstrate that IVIX is useful technical indicator for forecasting both up and downward market movement but its forecasting ability is superior for upward movements as compared to downward movements. 
Table II: Correlation between IVIX and PODV

\begin{tabular}{|c|c|c|c|c|c|c|c|c|c|c|c|}
\hline \multirow[b]{2}{*}{ NIFTY50 } & \multirow[b]{2}{*}{ AR } & \multirow[b]{2}{*}{ IVIX } & \multicolumn{3}{|c|}{ PODV Up or Down } & \multicolumn{3}{|c|}{ PODV Up } & \multicolumn{3}{|c|}{ PODV Down } \\
\hline & & & $\begin{array}{l}>= \\
1 \%\end{array}$ & $\begin{array}{l}>= \\
2 \%\end{array}$ & $\begin{array}{l}>= \\
3 \%\end{array}$ & $\begin{array}{l}>= \\
1 \%\end{array}$ & $\begin{array}{l}>= \\
2 \%\end{array}$ & $\begin{array}{l}>= \\
3 \%\end{array}$ & $\begin{array}{c}<= \\
-1 \%\end{array}$ & $\begin{array}{c}<= \\
-2 \%\end{array}$ & $\begin{array}{c}<= \\
-3 \%\end{array}$ \\
\hline AR & 1 & & & & & & & & & & \\
\hline IVIX & .01 & 1 & & & & & & & & & \\
\hline PODV up or down $1 \%$ & $-.06^{* *}$ & $.62^{* *}$ & 1 & & & & & & & & \\
\hline PODV up or down $2 \%$ & -0.01 & $.71^{* *}$ & $.77^{* *}$ & 1 & & & & & & & \\
\hline PODV up or down3\% & 0.01 & $.66^{* *}$ & $.64^{* *}$ & $.77^{* *}$ & 1 & & & & & & \\
\hline PODV up $1 \%$ & 0.04 & $.65^{* *}$ & $.78^{* *}$ & $.63^{* *}$ & $.56^{* *}$ & 1 & & & & & \\
\hline PODV up $2 \%$ & $.08^{* *}$ & $.77^{* *}$ & $.63^{* *}$ & $.86^{* *}$ & $.74^{* *}$ & $.66^{* *}$ & 1 & & & & \\
\hline PODV up 3\% & $.06^{* *}$ & $.69^{* *}$ & $.56^{* *}$ & $.68^{* *}$ & $.88^{* *}$ & $.49^{* *}$ & $.76^{* *}$ & 1 & & & \\
\hline PODV down $-1 \%$ & $-.14^{* *}$ & $.37^{* *}$ & $.82^{* *}$ & $.61^{* *}$ & $.48^{* *}$ & $.30^{* *}$ & $.37^{* * *}$ & $.41^{* *}$ & 1 & & \\
\hline PODV down $-2 \%$ & $-.11^{* *}$ & $.41^{* *}$ & $.66^{* *}$ & $.81^{* *}$ & $.54^{* *}$ & $.37^{* *}$ & $.41^{* *}$ & $.36^{* *}$ & $.67^{* *}$ & 1 & \\
\hline PODV down $-3 \%$ & $-.04^{*}$ & $.41^{* *}$ & $.53^{* *}$ & $.63^{* *}$ & $.80^{* *}$ & $.45^{* *}$ & $.47^{* *}$ & $.44^{* *}$ & $.40^{* *}$ & $.597^{* *}$ & 1 \\
\hline
\end{tabular}

${ }^{* *}$ Correlation is significant at the 0.01 level (2-tailed).

* Correlation is significant at the 0.05 level (2-tailed).

Table III presents output of regression models used to analyze the relationship of IVIX with ARSD. The values of ARSD are calculated using three lead or forward periods. ARSD with lead 21 is a measure of future one month volatility, ARSD 10 days is measure of future half month's volatility and similarly ARSD 5 is measure of future one week volatility. ARSD 21, 10, and 5 are computed using rolling standard deviations of 21,10 , and 5 leading values of daily Nifty returns respectively. The values of ARSD are regressed with IVIX and their other ARSD figures with different lead periods. The rationale is to analyze the impact of IVIX on ARSD values. If IVIX has effect on ARSD values then we can infer that IVIX has predictability capacity for future stock market volatility.

Table III: Relationship of IVIX and ARSD: Estimation Outputs

\begin{tabular}{|l|c|c|c|c|c|c|}
\hline & ARSD Lead 21 & $\begin{array}{c}\text { ARSD } \\
\text { Lead 21 }\end{array}$ & ARSD Lead 10 & $\begin{array}{c}\text { ARSD } \\
\text { Lead 10 }\end{array}$ & ARSD lead 5 & $\begin{array}{c}\text { ARSD } \\
\text { Lead 5 }\end{array}$ \\
\cline { 2 - 7 } & Model I & Model II & Model III & Model IV & Model V & Model VI \\
\hline C & 0.134 & $0.969^{* * *}$ & $-1.418^{* * *}$ & -0.208 & $-2.069^{* * *}$ & $-1.432^{* *}$ \\
\hline & $(0.402)$ & $(0.282)$ & $(0.483)$ & $(0.346)$ & $(0.624)$ & $(0.609)$ \\
\hline IVIX & $0.802^{* * *}$ & $0.273^{* * *}$ & $0.859^{* * *}$ & $0.367^{* * *}$ & $0.855^{* * * *}$ & $0.605^{* * *}$ \\
\hline & $(0.018)$ & $(0.022)$ & $(0.021)$ & $(0.025)$ & $(0.027)$ & $(0.042)$ \\
\hline ARSD Lead 10 & & $0.624^{* * *}$ & & & & \\
\hline & & $(0.020)$ & & & & \\
\hline ARSD Lead 5 & & $-0.032^{* *}$ & & $0.533^{* * *}$ & & \\
\hline & & $(0.016)$ & & $(0.014)$ & & \\
\hline ARSD Lag 5 & & -0.007 & & $0.040^{* *}$ & & $0.179^{* * *}$ \\
\hline & & $(0.016)$ & & $(0.014)$ & & $(0.033)$ \\
\hline ARSD Lag 10 & & 0.011 & & 0.008 & & $0.119^{* *}$ \\
\hline & & $(0.025)$ & & $(0.030)$ & & $(0.053)$ \\
\hline ARSD lag 21 & & 0.021 & & -0.007 & & -0.013 \\
\hline & & $(0.025)$ & & $(0.030)$ & & $(0.053)$ \\
\hline R-Squared & 0.556 & 0.785 & 0.499 & 0.747 & 0.372 & 0.410 \\
\hline Adj. R-Squared & & 0.784 & & 0.746 & & 0.408 \\
\hline
\end{tabular}




\begin{tabular}{l|c|c|c|c|c|c|}
\hline F-Statistics & & $1007.914^{* * *}$ & & $977.104^{* * *}$ & & $288.043^{* * *}$ \\
\hline No of Obs. & 1656 & 1656 & 1656 & 1656 & 1656 & 1656 \\
\hline$*, * *$, and $* * *$ \\
means the coefficient is significant at 1\%, 5\%, and 10\% level of significance \\
respectively. The values in the parentheses are standard errors.
\end{tabular}
.

Model I presents output of simple regression model with ARSD (Lead 21) as dependent and IVIX as independent variable. The beta coefficient is found to be significant at 1 percent level of significance. Moreover, the coefficient is positive which means that IVIX values positively impact ARSD with lead 21. The magnitude of the beta coefficient reveals that for 1 unit increase in current value of IVIX the ARSD value increases by 0.802 . As ARSD lead 21 values are computed using one month leading standard deviation of daily market returns, the finding depicts that IVIX has good forecasting ability for future short term (i.e. one month's) volatility. Additionally, the R-squared value reveals that around 55 percentage of variation in ARSD Lead 21 is explained by changes in IVIX. Hence, IVIX is a significant determinant of future stock market volatility.

Model II result reveals that future one month's volatility depends on current IVIX and only ARSD values with smaller lead periods. The beta coefficients associated with only IVIX, ARSD (10) and ARSD (5) are significant. The beta coefficients of lagged annualized rolling standard deviation, ARSD (-5), ARSD (-10) and ARSD (-21) are all insignificant. The result reveals that volatility persistence or memory process tends to occur for one month (i.e. 21 trading days) period. Most importantly, the beta coefficient associated with IVIX is highly significant and positive which means that increase in IVIX value increases forward one month volatility and vice versa. Similarly, Model III shows that IVIX has significant positive impact on ARSD with 10 days lead. It means the current IVIX value is good predictor of coming half month's volatility. The beta coefficient in is larger as compared to that of Model I which means per unit changes in IVIX values leads to relatively higher changes in ARSD with 10 days lead as compared to ARSD with 21 days lead. However, the Rsquared value of Model III is lower than that of Model I. The results reveal that although changes in IVIX has larger impact on coming half month's volatility as compared to one month's volatility, it explains stock market volatility of coming one month better.

The results of Models IV, V and VI are consistent with the previous findings. In Model IV, the beta coefficients associated with IVIX and ARSD (5) and ARSD (-5) are significant. It again reveals that the current volatility is affected by past volatilities occurring upto one month period (i.e. 21 trading days). Model V shows that IVIX is significantly and positively associated with forward one week's volatility. Finally, Model VI also reveals results in corroboration with previous models. The beta coefficient associated with ARSD (-10) is now significant. The adjusted R-squared value is the highest for Model II. The IVIX and ARSD (10) and ARSD (5) explain around 78.5 percent of variation in coming one month's future volatility. Overall, the results show that IVIX has good forecasting power for future volatility up to one month's period. The R-squared value is the highest for Model I (among models with IVIX as a single independent variable) which reveals IVIX is best predictor for coming one month's volatility. However, high current IVIX value which is a measure of market's expectation of future volatility is followed by slightly higher volatility in subsequent half month period as compared to the whole month.

Table IV: Relationship between IVIX and Lagged ARSD Values: Estimation Outputs

\begin{tabular}{|l|c|c|c|c|c|}
\hline & IVIX & IVIX & IVIX & IVIX & IVIX \\
\cline { 2 - 6 } & Model I & Model II & Model III & Model IV & Model V \\
\hline C & 14.411 & $11.620^{* * *}$ & $9.222^{* * *}$ & $11.612^{* * *}$ & $9.176^{* * *}$ \\
\hline & $(0.266)$ & $(0.273)$ & $(0.276)$ & $(0,272)$ & $(0.272)$ \\
\hline ARSD Lag 5 & $0.438^{* * *}$ & & & $0.067^{* * *}$ & $0.078^{* * * *}$ \\
\hline & $(0.014)$ & & & $(0.021)$ & $(0.019)$ \\
\hline ARSD Lag 10 & & $0.579^{* * *}$ & & $0.516^{* * *}$ & $0.078^{* *}$ \\
\hline
\end{tabular}




\begin{tabular}{|l|c|c|c|c|c|}
\hline & & $(0.014)$ & & $(0.025)$ & $(0.031)$ \\
\hline ARSD lag 21 & & & $0.699^{* * *}$ & & $0.557^{* * *}$ \\
\hline & & & $(0.014)$ & & $(0.028)$ \\
\hline R-Squared & 0.384 & 0.510 & 0.597 & 0.513 & 0.609 \\
\hline Adj. R-Squared & & & & 0.512 & 0.608 \\
\hline F-Statistics & & & & $873.947^{* * *}$ & $862.111^{* * *}$ \\
\hline
\end{tabular}

$*$, **, and *** means the coefficient is significant at 1\%, 5\%, and 10\% level of significance respectively. The values in the parentheses are standard errors.

Table IV presents the output of regression models used to analyze the impact of past stock market volatility in current IVIX values. Model I, II and III are simple regression models with ARSD values of lag 5, 10, and 21 as independent variables respectively. In Model IV, ARSD with 5 and 10 lags are included as independent variables and finally in Model V all lagged values of ARSD are included are explanatory variables. It is expected that past volatility in the market affects investors' expectations regarding future stock market volatility which in turn should affect current IVIX value. The results show that in Model I, II and III all the beta coefficients are positive and significant at 1 percent level of significance. It means the current value of IVIX depends on past stock market volatility. The values of beta coefficient and R-squared are highest for Model III which indicates that past one month's volatility has the largest impact on current IVIX values. The output for Model IV shows that both ARSD with lag 5 and 10 have impact on current IVIX value. Similarly, in Model V, beta coefficients associated with ARSD lags 5, 10 and 21 are all significant and positive. The result reveals that past volatility has effect on current IVIX level. In combination the findings show that current IVIX value is affected by stock market volatility in past month and the current IVIX is good predictor of future one month's volatility. This result indicates that volatility in Indian stock market can be forecasted for a period of two months (i.e. 42 trading days).

Table $\mathrm{V}$ shows the results of simple regression model of percentage days of volatility (PODV) on IVIX. The PODV values are calculated as forward one month's percentage of days the Nifty return changes by 1,2 and 3 percent or more. The current IVIX value is expected to be related with the future stock price movements. The beta coefficients for all IVIX values are significant and positive. It means that IVIX is positively related with future percentage change in stock prices. Higher IVIX value leads to higher percentage changes in future prices and vice-versa.

Table V: Relationship between IVIX and PODV: Estimation Results

\begin{tabular}{|c|c|c|c|c|c|c|c|c|c|}
\hline \multirow{2}{*}{} & \multicolumn{3}{|c|}{ PODV (Up or Down) } & \multicolumn{3}{c|}{ PODV (Up) } & \multicolumn{3}{c|}{ PODV (Down) } \\
\cline { 2 - 10 } & $1 \%$ & $2 \%$ & $3 \%$ & $1 \%$ & $2 \%$ & $3 \%$ & $-1 \%$ & $-2 \%$ & $-3 \%$ \\
\hline $\mathrm{C}$ & $2.44^{* * *}$ & $-11.75^{* * * *}$ & $-7.30^{* * *}$ & $-1.39^{* * *}$ & $-9.48^{* * *}$ & $-5.45^{* * *}$ & $3.50^{* * *}$ & $-2.74^{* * *}$ & $-2.514^{* * *}$ \\
\hline & $(0.94)$ & $(0.52)$ & $(0.48)$ & $(0.54)$ & $(0.37)$ & $(0.52)$ & $(0.74)$ & $(0.42)$ & $(0.519)$ \\
\hline IVIX & $1.38^{* * *}$ & $0.92^{* * *}$ & $0.43^{* * *}$ & $0.85^{* * *}$ & $0.63^{* * *}$ & $0.31^{* * *}$ & $0.54^{* * *}$ & $0.31^{* * *}$ & $0.164^{* * *}$ \\
\hline & $(0.04)$ & $(0.02)$ & $(0.02)$ & $(0.02)$ & $(0.01)$ & $(0.02)$ & $(0.03)$ & $(0.01)$ & $(0.023)$ \\
\hline $\mathrm{R}^{2}$ & 0.40 & 0.49 & 0.19 & 0.43 & 0.47 & 0.09 & 0.14 & 0.14 & 0.030 \\
\hline $\mathrm{N}$ & 1656 & 1656 & 1656 & 1656 & 1656 & 1656 & 1656 & 1656 & 1656 \\
\hline
\end{tabular}

Higher beta coefficients for IVIX are found for PODV up or down. It indicates that IVIX has more forecasting power for two-way stock price movements. The coefficients are the lowest for PODV down which means IVIX has relatively lower predictability for downward price movements as compared to upward price movements. Moreover, the values of R-squared are higher for PODV up or down and PODV up as compared to PODV down. Therefore, the results imply that IVIX is a more efficient bullish indicator. Additionally, the R-squared values are higher for PODV 1 and 2 percent as 
compared to 3 percent. It indicates IVIX has more forecasting ability of future stock market volatility of lower magnitude and less predictability for high stock price movements.

\section{Conclusions}

The study results reveal that India VIX is a good indicator of future short-term stock market volatility. It is found to be an efficient tool to forecast future one month volatility. It has higher predictability for upward market movement as compared to downward movements. Hence, IVIX is more a bullish indicator. Additionally, the accuracy of forecasts provided by IVIX is higher for low magnitude future price changes relative to higher stock price movements. The current value of IVIX is found to be affected by past period volatility up to one month and IVIX has forecasting ability for future onemonth's volatility which means the volatility in the Indian stock markets can be forecasted up to 60 days. As IVIX is found to have good forecasting ability for future short-term volatility investors should make trading decisions based on IVIX. The IVIX futures contract can be used to hedge their portfolios against volatility risk. More products based on IVIX should be introduced so that investors will have wider choices of financial assets for volatility trading. Similarly, volatility index based on other indices like mid cap, small cap and sectoral indices should be developed so that investors have an indicator to measure expected future volatility segment and sector-wise.

\section{REFERENCES}

Bagchi, D. (2012). Cross-sectional analysis of emerging market volatility index (India VIX) with portfolio returns. International Journal of Emerging Markets, 7(4), 383-396.

Banerjee, A., \& Kumar, R. (2011). Realized volatility and India VIX. Institute of Management Calcutta, WPS No. 688.

Banerjee, A., \& Sahadev, S. (2006). Modeling daily volatility of the Indian stock market using intraday data. IIMK, WPS No. 588/ March 2006.

Becker, R., \& Clements, A. E. (2007). Are combination forecasts of NIFTY 50 volatility statistically superior? National Center for Econometric Research Working Paper Series.

Becker, R., Clements, A. E., \& McClelland, A. (2009). The jump component of S\&P 500 volatility and the VIX index. Journal of Banking \& Finance, 33(6), 1033-1038.

Becker, R., Clements, A. E., \& White, S. I. (2006). Does implied volatility provide any information beyond that captured in model-based volatility forecasts? Journal of Banking \& Finance, $45,2535-2549$.

Corrado, C. J., \& Miller, T. W. (2005). The forecast quality of CBOE implied volatility indexes. Journal of Futures Markets, 25, 339-373.

Chakrabarti, P. (2015). Examining Contemporaneous Relationship Between Return of Nifty Index and India VIX. International Journal of Financial Management, 5(2).

Dixit, A., Yadav, S. S., \& Jain, P. K. (2010). Informational efficiency of implied volatilities of S\&P CNX Nifty index options, Journal of Advances in Management Research, 7(1), $32-57$.

Fleming, J. (1998). The quality of market volatility forecasts implied by S\&P 100 index option prices. Journal of empirical finance, 5(4), 317-345.

Frinjns, B., Tallau, C., \& Rad-Tourani, A. (2010). The information content of implied volatility: Evidence from Australia. Journal of Futures Markets, 30(2), 134-155. 
Giot, P. (2004). Relationships between implied volatility indexes and stock index returns. Journal of Portfolio Management, 31, 92-100.

Hung, J., Xi, N., \& Hua. C. (2009). Using VIX index and range-based volatility to enhance the volatility forecasting performance of GARCH models. Economics Bulletin, 2592-2604.

Jiang, G. J., \& Tian, Y. S. (2007). Extracting model-free volatility from option prices: An examination of the VIX index. Journal of Derivatives, 14(3).

Karmakar, R. (2003). Stock return volatility and market crisis in emerging economies. Review of Accounting and Finance, 3, 59-83.

Kumar, S. (2010). The behaviour of India's volatility index. Indian Management Journal, 2(2).

Kumar, S. (2012). A first look at the properties of India's volatility index. International Journal of Emerging Markets, 7(2), 160-176.

Lu, K. J., Wang, G., \& Lee, R. (2012). The VIX market volatility index and US stock index returns. Journal of International Business and Economics, 11(4), 167-179.

Poon, S. H., \& Granger, C. W. (2003, June). Forecasting volatility in financial assets. Journal of Economic Literature, 478-539.

Ryu, D. (2012). Implied volatility index of KOSPI200: information contents and properties. Emerging Markets Finance and Trade, 48(sup2), 24-39.

Sarwar, G. (2012). Is VIX an investor fear gauge in BRIC equity markets? Journal of Multinational Financial Management, 22(3), 55-65.

Thenmozhi, M., \& Chandra, A. (2013). India volatiltiy (India VIX) and risk management in Indian stock market, NSE Working Paper.

Whaley, R. (2000). The Investor Fear Gauge. The Journal of Portfolio Management, 26 (2000), 1217.

Whaley, R. E. (2009). Understanding the VIX. Journal of Portfolio Management, 35, 98-105.

Zhang, J. E. (2006). VIX futures. Journal of Futures Markets, 26(6), 521-531. 


\section{Appendix I : Trend of IVIX and Volatility Measures}

Figure I: Trend of IVIX and Annualized 21 Days Leading Rolling Standard Deviation

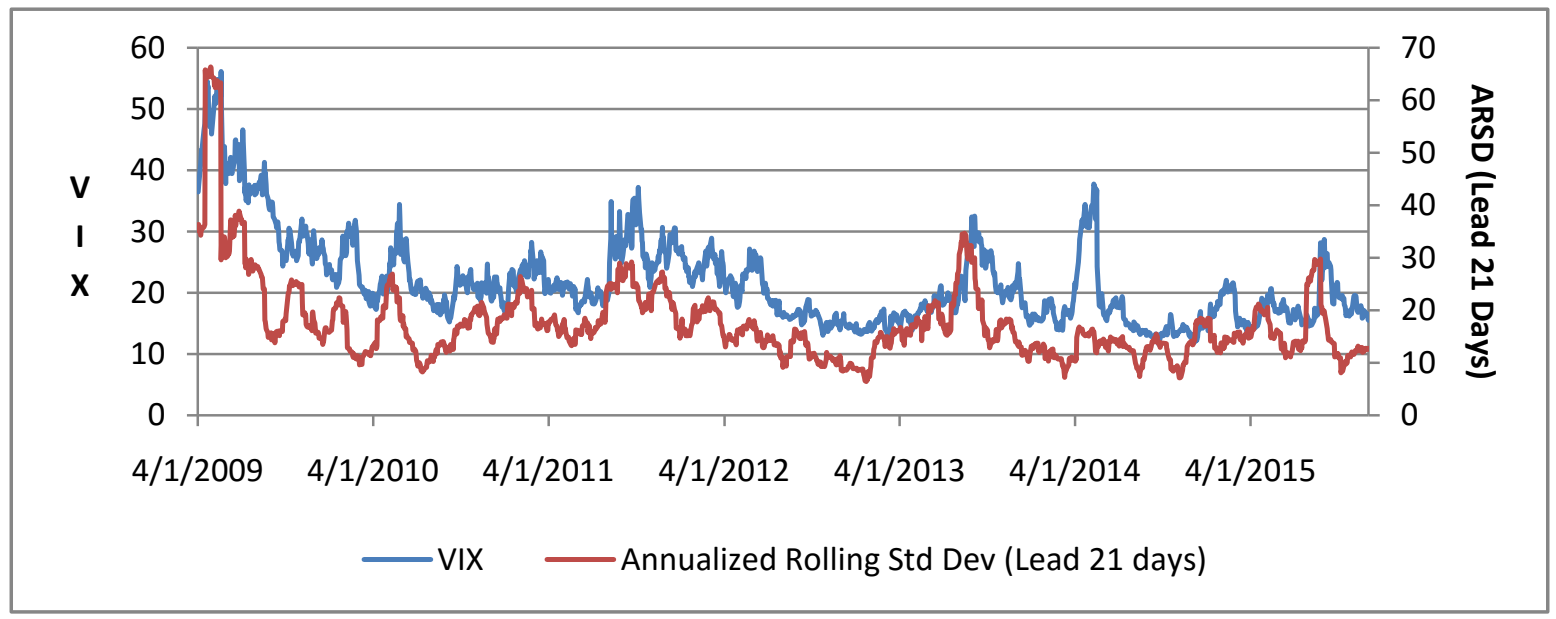

Figure II: Trend of IVIX and Annualized 21 Days Lagging Rolling Standard Deviation

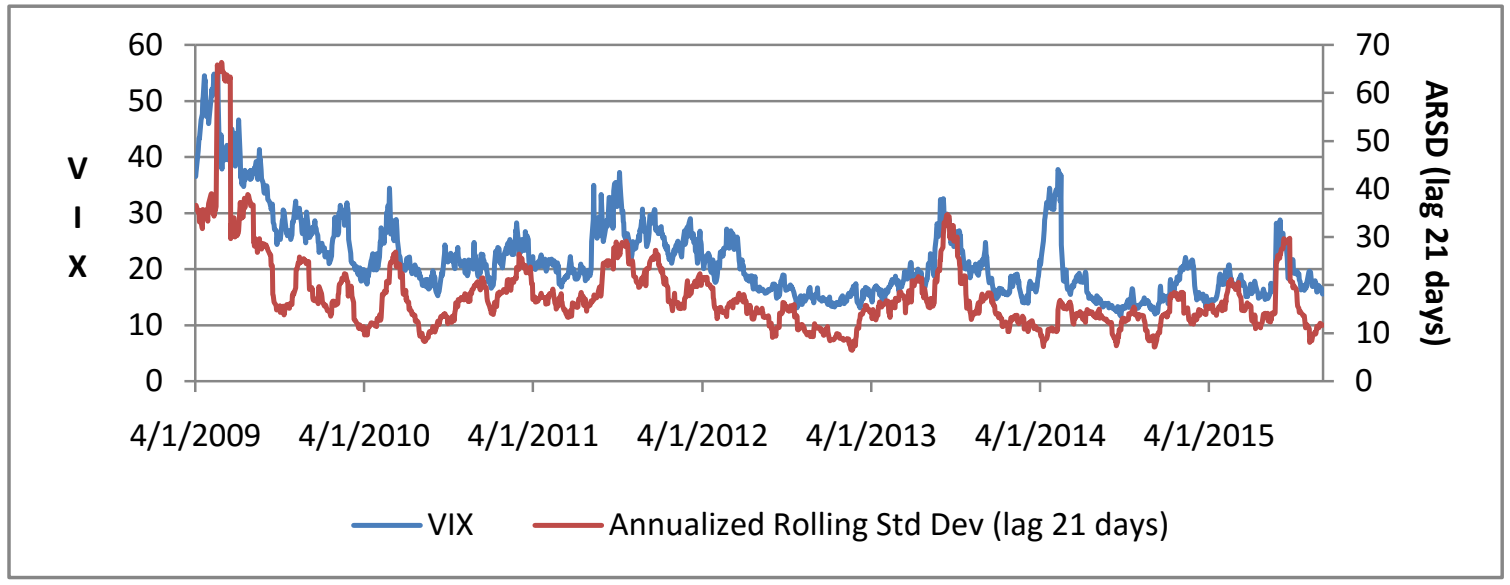

Figure III: Trend of IVIX and Forward One-month Percentage of Days of Volatility

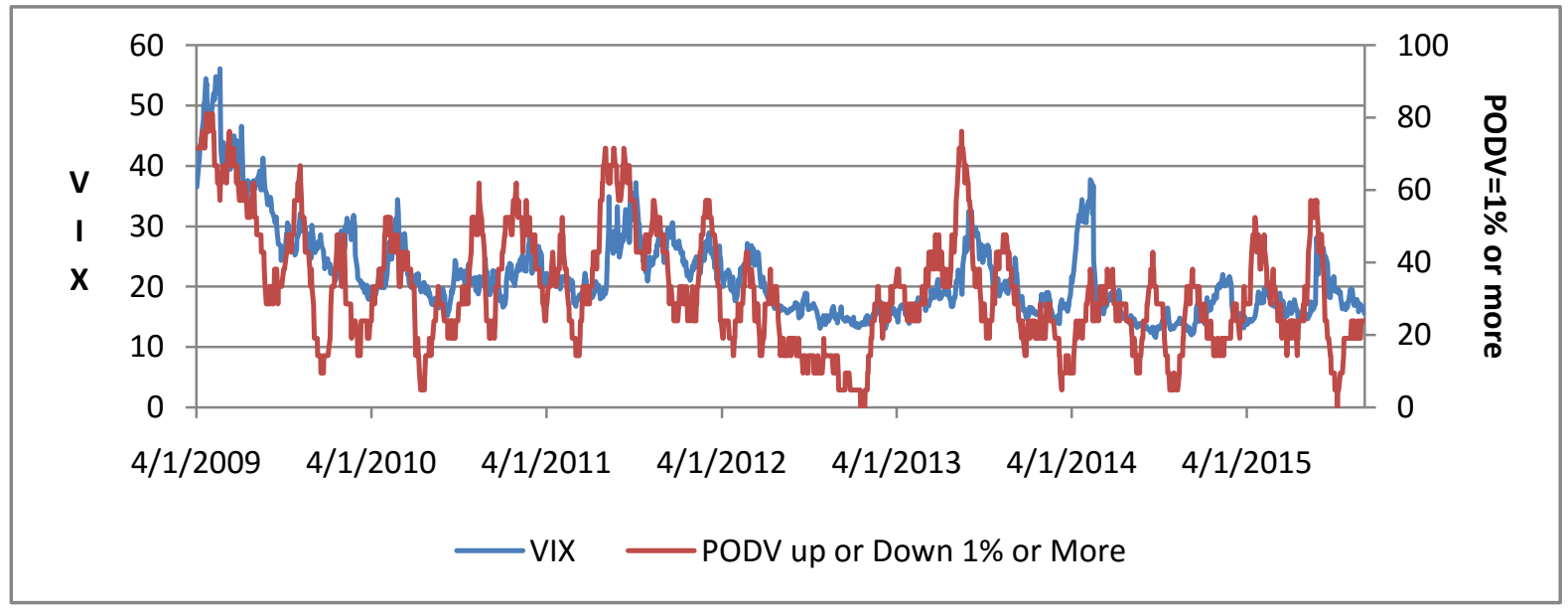


Appendix II: IVIX and Forward Volatility of Nifty 50 Returns

\begin{tabular}{|c|c|c|c|c|c|c|c|c|c|}
\hline \multirow{3}{*}{ YEAR } & \multirow{2}{*}{\multicolumn{3}{|c|}{ IVIX }} & \multirow{2}{*}{\multicolumn{3}{|c|}{$\begin{array}{c}\text { Nifty } 50 \text { ARSD } \\
\text { Annualized } 21 \text { days }\end{array}$}} & \multirow{2}{*}{\multicolumn{3}{|c|}{$\begin{array}{c}\text { NIFTY } 50 \text { PODV } \\
(+ \text { or }-2 \%)\end{array}$}} \\
\hline & & & & & & & & & \\
\hline & Mean & Min & Max & Mean & Min & Max & Mean & Min & Max \\
\hline 2009 & 35.752 & 22.940 & 56.070 & 28.802 & 13.499 & 66.327 & 21.506 & 0.000 & 42.857 \\
\hline 2010 & 21.814 & 15.220 & 34.370 & 15.946 & 8.241 & 26.871 & 5.933 & 0.000 & 23.810 \\
\hline 2011 & 23.836 & 16.730 & 37.190 & 20.489 & 13.240 & 29.159 & 12.570 & 0.000 & 38.095 \\
\hline 2012 & 19.723 & 13.040 & 28.920 & 14.370 & 8.405 & 22.393 & 4.971 & 0.000 & 19.048 \\
\hline 2013 & 18.889 & 13.070 & 32.490 & 17.151 & 6.428 & 34.669 & 8.438 & 0.000 & 33.333 \\
\hline 2014 & 17.107 & 11.565 & 37.705 & 12.765 & 7.122 & 18.492 & 2.127 & 0.000 & 9.524 \\
\hline 2015 & 17.814 & 13.143 & 28.718 & 15.633 & 8.068 & 29.734 & 4.699 & 0.000 & 19.048 \\
\hline $\begin{array}{l}\text { Aggregate } \\
(2009-15)\end{array}$ & 21.661 & 11.565 & 56.070 & 17.483 & 6.428 & 66.327 & 8.155 & 0.000 & 42.857 \\
\hline
\end{tabular}

